\title{
MIGRACIONES INTERNACIONALES Y RACISMO CULTURAL EN ARGENTINA
}

\section{INTERNATIONAL MIGRATION AND CULTURAL RACISM IN ARGENTINA}

\author{
Gilda Ivana Gonza* \\ Anahí Patricia González**
}

RESUMEN

\begin{abstract}
El artículo aborda las representaciones sociales sobre la identidad nacional y la "cultura" migrante que construyen docentes y miembros del poder judicial en Argentina, visibilizando el "racismo" cultural que atraviesa dichas representaciones y las relaciones de conflicto entre nativos y migrantes, vinculadas al acceso a los derechos. Para el análisis se recurrió a entrevistas individuales $y$ grupales realizadas a dichos actores institucionales en Buenos Aires, durante los años 2008-2014.
\end{abstract}

PALABRAS CLAVE: IDENTIDAD * NACIÓN * MIGRANTES* NATIVOS * RACISMO CULTURAL

\section{ABSTRACT}

The article approaches the social representations on national identity and migrant "culture" build that build teachers and members of the judiciary in Argentina, making visible the cultural "racism" that runs through such representations and relationships of conflict between natives and migrants, linked to access to rights. For the analysis were employed focus groups and individual interviews made to such institutional actors in Buenos Aires during the years $2008-2014$.

KEYWORDS: IDENTITY * NATION $*$ MIGRANTS $*$ NATIVES $*$ CULTURAL RACISM

* Instituto de Investigaciones Gino Germani, Universidad de Buenos Aires. ivanagonza@gmail.com

** Instituto de Investigaciones Gino Germani, Universidad de Buenos Aires anahipgonzalez@gmail.com 


\section{INTRODUCCIÓN}

En Argentina, las migraciones son un fenómeno de antigua data. Así, a fines del siglo XIX $y$ comienzo del siglo xx se producen las olas migratorias de mayor envergadura, fundamentalmente de origen europeo, en particular italianos y españoles (Devoto 1992). A partir de la segunda mitad del siglo xx, se modifica la cantidad $y$ el origen de los migrantes internacionales que arriban al territorio. De esta manera, se evidencia un incremento del peso relativo de los migrantes sudamericanos frente a los de Europa.

Asimismo, hacia la década de 1960, crecerá la presencia de migrantes de origen asiático, situación que aún perdura. Cabe mencionar también la llegada, en los últimos años, de colectivos provenientes de algunos países de África. Particularmente, la migración limítrofe, si bien ha aumentado con el paso de las décadas, desplazando en importancia numérica a la no limítrofe, solo ha representado históricamente entre el $2 \%$ y el $3 \%$ del total de la población, llegando a ser, a comienzos de la década de 1990, más del 50\% del total de la población migrante en Argentina (Benencia 2003).

Teniendo como trasfondo el escenario descrito anteriormente, el presente artículo analiza los resultados de dos proyectos de investigación uвAсут ${ }^{1}$ :"Exclusión, control social $y$ diversidad en la relación entre el migrante externo y las instituciones educativa y judicial" (Programación Científica 2008-2010) $y$ "Diversidad etno-nacional y construcción de desigualdades en las instituciones escolar y judicial. Un desafío teórico-metodológico en el abordaje de los casos del амва y la provincia de Mendoza" (Programación Científica 2011-2014). Ambos proyectos han tenido como objetivos indagar sobre las representaciones sociales que los nativos (docentes, en el primer caso y miembros del poder judicial, en el

1 Los UBACYT son proyectos de investigación acreditados y financiados por la Universidad de Buenos Aires, Argentina. Anualmente, los docentes de las distintas Facultades tienen la posibilidad de presentar propuestas de investigación. Las mismas son evaluadas por Comisiones Técnicas Asesoras y finalmente, el Consejo Superior de la Universidad selecciona los proyectos a acreditarse. segundo) construyen acerca de los migrantes internacionales llegados, entre el periodo 2008-2014 a Argentina.

En el presente trabajo se analizan las representaciones sociales de los entrevistados partiendo de la definición de Jodelet (1986), quien enmarca la existencia de estas en la necesidad que tienen todos los sujetos de saber a qué atenerse ante el entorno que los rodea, así:

... ante un mundo de objetos, personas, sucesos e ideas no estamos equipados únicamente de automatismos, ni estamos aislados en un medio social, sino que lo compartimos con otros, nos apoyamos en ellos - a veces en el acuerdo, a veces conflictivamente - para comprenderlo, controlarlo o afrontarlo... Ellas nos orientan en la manera de designar $y$ definir conjuntamente los diferentes aspectos de nuestra realidad diaria, en la manera de interpretarlos, influir sobre ellos $y$, en caso contrario, tomar una posición ante ellos y defenderla (Jodelet 1986, 203).

La hipótesis que subyace al trabajo es que en las representaciones sociales de los entrevistados, la construcción identitaria del migrante se produce a partir de un discurso atravesado por elementos propios del denominado racismo cultural. Asimismo, en este proceso relacional, los nativos construyen su propia identidad en oposición a la de los migrantes, jerarquizando identidades nacionales y culturas. Esta construcción identitaria diferencial culmina en un discurso que establece distinciones en el acceso a derechos, transfigurándose así la "diferencia" en "desigualdad".

Teniendo en cuenta lo anterior, el artículo se estructura del siguiente modo. En primer lugar, se realizan algunas especificaciones sobre la estrategia metodológica empleada. Seguidamente, se analizan los resultados de los grupos focales y de las entrevistas a los miembros del poder judicial en función de lo planteado en la hipótesis. Con el fin de ordenar el análisis, el mismo se presenta a partir de las siguientes dimensiones: representaciones sobre la construcción de la identidad nacional 
y la "cultura" migrante, la jerarquización de culturas y el racismo cultural, identidad nacional, migraciones de ultramar y regionales $y$, finalmente, de la negativización de la "cultura migrante" a la jerarquización de derechos. Por último, se presentan algunas reflexiones finales.

\section{ESTRATEGIA METODOLÓGICA ${ }^{2}$}

El análisis se focalizó en la mirada que el nativo construye acerca del migrante internacional. Es decir, la unidad de análisis de la investigación fueron los nativos pertenecientes a las instituciones educativa $y$ judicial. El modo de abordaje para ambos universos de estudio supuso el diseño de una estrategia de carácter cualitativa que buscó conocer el decir de los docentes y de los miembros del sistema judicial.

Para el caso particular del universo educación, se trabajó con catorce grupos focales realizados a docentes de Capital Federal y Gran Buenos Aires durante los años 2008-2011. La realización de dichos grupos focales se efectuó teniendo en cuenta dos variables relevantes para la posterior interpretación y análisis: nivel de inserción docente (primario, secundario) y tipo de institución (pública, privada confesional, privada laica). Asimismo, "...el grupo de discusión como espacio de reflexión y debate permitió la construcción de un discurso colectivo, en el que si bien cada sujeto habla por sí, lo hace en alianzas tácitas con otros" (Ibáñez 1992, citado en González y Plotnik 2011). Esta característica de los grupos focales ha sido tomada en cuenta también en la etapa del análisis.

Respecto al universo de justicia, se realizaron entrevistas en profundidad semiestructuradas a miembros del sistema judicial de la Provincia de Buenos Aires y de la Ciudad de Buenos Aires durante los años 2012-2014. Se entrevistó, con una misma guía de pautas, a jueces, fiscales, secretarios, asesores tutelares, jefes de despacho, directores de áreas de denuncias y asistencia a la víctima, escribientes y prosecretarios. El número final de entrevistas (cincuenta) resultó de la

2 La descripción metodológica que se realiza en este apartado puede encontrarse también en los dos proyectos UBACYT reseñados en la introducción. implementación metodológica conocida como saturación teórica de la muestra (Strauss y Corbin 2002).

Para el procesamiento del material, de ambos universos de estudio, se desgrabó textualmente las entrevistas grupales e individuales y se prosiguió grillando las transcripciones de los audios. Asimismo, se analizó a partir del método de comparación constante (Strauss y Corbin 2002).

\section{ALGUNAS ESPECIFICACIONES ACERCA DE LA POLÍTICA Y LEGISLACIÓN MIGRATORIA ARGENTINA}

Tal cómo se especificó en la introducción, Argentina es un país cuya conformación estatal-nacional se ha visto atravesada por la llegada de migrantes; no obstante, actualmente, los extranjeros que llegan no provienen fundamentalmente de Europa sino que el flujo migratorio podría enmarcarse dentro de lo que se denomina migración sur-sur.

De este modo, se ha incrementado el número de migrantes provenientes de América Latina y el Caribe en proporción a los de otros países del mundo. Así, en el 2000, el 68\% provenía de América Latina y el Caribe, mientras que hacia el 2010 lo eran el 80\%, al tiempo que, los nacidos en otros países del mundo pasaron de ser el 32\% en el año 2000 al 18\% en el año 2010 (Martinez, Cano y Contrucci 2014). No obstante, cabe aclarar que el número de personas extranjeras que habitan en el país se ha mantenido en el porcentaje promedio, que históricamente se ha dado en el territorio, esto es alrededor de un $4 \%$ de la población total.

Lo que interesa recalcar, como señala Grimson (2006), es que si bien se produjeron cambios en términos socio-demográficos en relación a la migración hacia Argentina, estos no refieren a un incremento en la cantidad de migrantes. El proceso involucra en realidad dos aspectos. Por un lado y como se mencionó, la proporción de inmigrantes limítrofes sobre el total de extranjeros ha aumentado constantemente en las últimas décadas, mientras que la proporción de europeos sobre el total tendió a descender. En segundo término, los migrantes que históricamente se asentaban en zonas 
de frontera o en territorios marginales, en las últimas décadas han tendido a desplazarse hacia las capitales de las ciudades más importantes del país. Así, hacia las décadas de los 80 y 90, el Área Metropolitana de Buenos Aires pasó a ser la zona que concentraba la mayor proporción de migrantes limítrofes. Estos factores contribuyeron a una modificación en el régimen de visibilidad étnica e incluyó dos procesos simultáneos; por un lado, una mayor visibilidad étnica de los migrantes limítrofes, en términos de reivindicación de derechos y en tanto sujetos políticos, por el otro lado, una mayor visibilidad en términos de discriminación y xenofobia por parte de los nativos, que se exacerbaría durante las década de los noventa (Grimson 2006).

Es importante señalar que Argentina ha sancionado en el año 2004, un nuevo marco normativo, que sustituye a la denominada "Ley Videla", promulgada durante la última dictadura militar y vigente hasta el 2003. La Ley 25871 (reglamentada en el 2010) presenta avances sustanciales, respecto a su antecesora, en relación al reconocimiento de los derechos humanos de los extranjeros innovando de esta manera en relación a la mayoría de las legislaciones migratorias en la región.

Específicamente, la "Ley Videla", atravesada por la Doctrina de Seguridad Nacional, establecía que la Dirección Nacional de Migraciones gozaba de la facultad de controlar el ingreso, egreso y permanencia de los extranjeros ejerciendo el poder de policía y pudiendo detener sin orden judicial a inmigrantes irregulares. En otras palabras, legislando en contra, fundamentalmente, de la migración sudamericana, la "Ley Videla" ( $\mathrm{n}^{\circ} 22.439$ ) actuaba como un "dispositivo generador de ilegalidad" (Courtis, 2006). Del mismo modo, esta Ley instituía una serie de restricciones respecto al reconocimiento a ciertos derechos, tales como la salud, educación, seguridad social, etc., vinculándolas con la situación de regularidad o irregularidad del extranjero. En cambio, los artículos 6, 7 y 8 de la Ley actual establecen el reconocimiento de los derechos antes mencionados, al tiempo que insta a diversas instituciones estatales a brindar información a los migrantes que pudieran encontrarse en estado de irregularidad migratoria sobre los trámites a seguir para modificar dicha situación (artículo 9, Ley 25871). De esta manera, se reconoce el derecho a migrar como un derecho humano, se incorpora el principio de reunificación familiar, se otorga a ciudadanos de países miembros y asociados del MERCosur, la nacionalidad como único criterio de radicación $y$ finalmente, se reconoce al migrante como sujeto de derecho al incluir la posibilidad de presentar recursos judiciales frente a disposiciones de expulsión emitidas por la Dirección Nacional de Migraciones.

No obstante, sin desmerecer los avances que estas modificaciones normativas suponen, la implementación de la ley conlleva, entre otros obstáculos, el desafío de derribar una serie de preconceptos, prejuicios y representaciones sociales acerca de los migrantes. Respecto a esta dimensión simbólica de la problemática es que se tratan las páginas que siguen. Es decir, se considera que no resulta menor entender que si bien las modificaciones legislativas son un paso necesario y fundamental para un avance en el reconocimiento de los migrantes como iguales a los nativos, las mismas resultarán insuficientes sin un cambio en el imaginario acerca del lugar que ocupan/ deberían ocupar los migrantes en el entramado social. Es en este sentido, que la escuela y la justicia, se presentan como dos instituciones centrales para la indagación acerca de dicho imaginario social.

\section{REPRESENTACIONES SOBRE LA CONSTRUCCIÓN DE LA IDENTIDAD NACIONAL Y LA "CULTURA MIGRANTE"}

Una de las funciones centrales de las instituciones estatales es la de generar la idea de "comunidad imaginaria" a la que refiere Anderson (1993). Es decir, producir al sujeto nacional $y$ a la nacionalidad como el grupo de pertenencia por excelencia. Se coincide con Balibar (2005, 70) cuando señala que "no hay identidad dada; solo hay identificación". En particular, en relación con la cuestión de la identidad nacional, se concibe como una construcción, lo cual remite a la problemática de "la historicidad del Estadonación y de la forma nación en sí" (Balibar 2005, $66)$. Es decir, que las representaciones sociales 
que posee el nativo acerca del otro, al igual que la propia noción de identidad nacional, son construcciones socio-históricas, enmarcadas desde la constitución misma del Estado-Nación argentino. Como sostiene Balibar:

... lo que hay en realidad es la producción de una etnicidad "ficticia", en el sentido que ninguna nación posee naturalmente una base étnica dada. Sin embargo, el término "ficción" no se debe tomar como mera ilusión sin efectos históricos, sino en el sentido de "fabricación”, con efectos institucionales y subjetivos $(1991,148)$.

En el proceso de edificación identitaria, las Instituciones (escuela, justicia, entre otros) han cumplido y aún cumplen un rol fundamental al reducir la multiplicidad y complejidad de las variadas identificaciones posibles, permitiendo su jerarquización y trasmitiendo la identidad nacional por medio de "los rasgos de hábito o de rito" y de "los rasgos de creencia y de fe", es decir, mediante la "cultura" (Balibar 2005). En las representaciones sociales, que los miembros del sistema judicial construyen acerca de la identidad nacional, aparecen los elementos constitutivos de la Nación, reseñados anteriormente. Así, pueden leerse testimonios de los miembros de las instituciones escolar y judicial en los que se auto-representan como pertenecientes a una comunidad "unívoca", en base a ciertos elementos comunes: la "cultura", la historia, la tierra y el idioma.

La identidad nacional, digamos, de algún modo son como tres cosas ¿no? Por un lado, es aferrarse a una tierra a una cultura, a una historia, $y$ creo que, de algún modo esas tres cosas, confluyen en lo que sería más importante de esto, que es un proyecto futuro común, digamos. Vos tenés la historia, tenés la tierra, tenés la cultura, y a todo esto vos decís: vamos todos para allá. Entonces, en eso es donde, termina siendo lo igualitario y lo integrador, en decir: vamos para allá (Juan, Fiscal, entrevistado por miembro del equipo de investigación UBACYT, 01 de agosto de 2010).
En este sentido, la idea de una "cultura unívoca”, presente en los fragmentos de entrevistas, que esencialmente compartirían todos los que forman parte del colectivo nacional, se refuerza recurriendo a elementos del pasado, del presente y también del futuro. Dichas referencias a la univocidad temporal de la comunidad imaginada, hablan de la "ilusión retrospectiva" de la identidad nacional a la que hace referencia Balibar $(1991,135)$ y que supone que se trasmite "una sustancia invariable". En los testimonios de docentes recogidos a través de grupos focales, se encuentran referencias a esta ilusión, en los cuales se afirma la necesidad de "revalorizar lo nuestro" como imperativo acuciante frente a la presencia de culturas "extrañas" y "desviadas":

Yo creo que hay que hacer una revisión interna de cada uno y revalorizar lo nuestro; nuestra tierra, nuestras costumbres. Reclamar otra vez el feriado de San Martín de Tours, que se perdió; salir a buscar nuestras raíces y enarbolarlas y sentirnos orgullosos de lo que somos. Primero hay que priorizar lo argentino (Grupo focal compuesto por docentes de escuelas primarias públicas, coordinado por miembro del equipo de investigación UBACYт, 18 de mayo de 2005).

Se advierte, una vez más, que en los discursos de los entrevistados opera cierta mirada sustancialista acerca de la identidad nacional como expresión del nacionalismo. Más aún, como se refirió en la entrevista citada anteriormente, ante la presencia "masiva" de los migrantes de países limítrofes se evidencia un pedido por volver a "nuestras raíces" y "costumbres", subyaciendo una visión esencialista del "nosotros nacional". Respecto de este punto, Calhoun (2008) sostiene que esta es una característica propia a través de la cual opera el nacionalismo, en tanto que no toma en cuenta las variaciones de la identidad nacional en búsqueda de cierta coherencia e integración interna.

De acuerdo a este autor, el nacionalismo funciona en parte porque las identidades nacionales, por lo general, aparecen de algún modo como preexistentes y naturalizadas. La 
identidad nacional se presenta "como si" los individuos habitaran culturas intrínsecamente coherentes y unívocas. Ahora bien, dicha unidad étnica y nacional, dada por supuesta, viene a ser minada con la presencia del migrante internacional.

Asimismo, las imágenes estigmatizadoras de los entrevistados, presentes en los discursos sobre la identidad nacional, se encuentran entrelazadas con las representaciones sociales acerca de la "cultura del migrante", de sus "personalidades" e idiosincrasias —que operan de igual modo como mácula- sobre la otredad migrante. En otros términos, en la definición del "nosotros nacional" subyace quiénes son los "otros", a los cuales es preciso definir, ubicar, fijar, describir y catalogar como esencial $y$ negativamente diferentes.

Los "otros" migrantes son tanto los que llegan actualmente como los que han arribado a fines del siglo xix y principios del xx. No obstante, las representaciones sociales que docentes $y$ miembros del poder judicial elaboran sobre unos y otros extranjeros distan, en la mayoría de los aspectos, de ser iguales. Es decir, a los efectos de presentar ordenadamente el análisis y en continuidad con el apartado presente, se procederá a presentar los resultados del análisis de las representaciones sobre la identidad nacional en oposición con la que construyen los entrevistados sobre la identidad del migrante "tradicional" y el actual, intentando evidenciar así las diferencias y similitudes en el lugar que unas $y$ otras representaciones sobre la identidad migrante ocupan en la edificación de la identidad de los nativos argentinos. Luego, se profundizará en la presentación de los datos referidos a los modos como el racismo cultural se manifiesta en los prejuicios y percepciones discriminatorias acerca de los migrantes actuales. Finalmente, se abordará el vínculo entre dichas percepciones con la cuestión del reconocimiento de derechos de los extranjeros en Argentina.

\section{IDENTIDAD NACIONAL, MIGRACIONES DE ULTRAMAR Y REGIONALES}

Como se ha hecho alusión, las migraciones denominadas comúnmente como "tradicionales" son aquellas de origen europeo producidas a fines del siglo xix y comienzos del xx. A partir de lo analizado en las entrevistas a miembros de la institución escolar y judicial, se puede advertir que la "migración tradicional" es visualizada desde el imaginario de los entrevistados como "aportante" a la identidad nacional de elementos positivos, tales como, la "cultura de trabajo", el esfuerzo individual, $y$ valores culturales y morales de "calidad", contrariamente a la caracterización, que reciben los migrantes sudamericanos actuales, en tanto "oportunistas" o en algunos casos "delincuentes"

...cuando vinieron los antepasados también trabajaban como bestias, los italianos, los españoles, nadie los ayudaba, no les daban plan trabajar ${ }^{3} .$. Y lo que yo veo, es como que ahora, mucho de estas migraciones es como que exigen o piden o se sienten discriminados, o exigen al gobierno, o piden algo... antes cuando mi abuelo venían de España qué le iba a pedir al gobierno, ¡Gracias que trabajaba!, que exigencia le voy a pedir... Había más cultura del trabajo y esfuerzo, hoy se quiere todo fácil y ya (Grupo Focal compuesto por docentes de escuelas secundarias privadas, coordinado por miembro del equipo de investigación UBACYT, 30 de abril de 2005).

...creo que esos inmigrantes trajeron sus costumbres, sus culturas, en las que nosotros nos formamos. Entonces vemos una distinción, y nos formamos, o sea nuestros abuelos, nuestros padres, nos formaron en esa cultura. Entonces es como que se ven diferencias. Y entiendo que hoy por hoy la justicia está siendo puesta en crisis, fundamentalmente, por el retraso que existe producto del avance demográfico. O sea, de la cantidad de personas, es un Poder Judicial preparado para determinada cantidad y calidad de personas (Mariano, Prosecretario, entrevistado por miembro del equipo de investigación UBACYT, 18 de agosto de 2010).

\footnotetext{
$3 \quad$ Se trata de un subsidio estatal a desempleados.
} 
La inmigración europea tenía una cultura del trabajo más inculcada, no sé. Eso es la diferencia. -imuchos vienen a trabajar, obviamente! $-y$ bueno, tienen suerte, consiguen un trabajo; $y$ otros vienen a sobrevivir como pueden, y dentro de ese "como pueden" también hay bastante delincuencia (Silvina, escribiente, entrevistada por miembro de equipo de investigación UBACYT, 18 de agosto de 2010).

En suma, en la conformación de la identidad nacional, la migración tradicional o de ultramar se presenta como un aporte fundamental, siendo muy extenso el imaginario que refiere a que los argentinos "descendemos de los barcos", es decir, que "nos identificamos" con aquella migración catalogada positivamente. Por el contrario, las características culturales de los migrantes de países limítrofes y del Perú ${ }^{4}$, son construidas discursivamente como sumamente alejadas y por ello, opuestas al "nosotros" nacional (Grimson 2006) ${ }^{5}$ :

4 Se incluye a Perú dentro de la categoría "migrantes limítrofes", aunque no lo sean, porque existe cierta homogeneidad en las representaciones entre todas estas comunidades. Resultado de una serie de investigaciones UBACYT en las que se ha participado y se ha podido evidenciar que “... los diferentes países que forman la comunidad migrante limítrofe asumen representaciones similares que las asignadas a los migrantes provenientes de Perú; es decir, (...) Perú se comporta como un país limítrofe..." ( Crosa Pottilli et ál. 2009).

Como sostiene Grimson (2006), se evidencia un persistente imaginario nacional mediante el cual se atribuye como una de las bases fundantes de la identidad nacional a la inmigración europea de mediados del siglo XIX, por lo que la identificación nacional se emparenta más con lo europeo que con lo mestizo y/o latinoamericano ( $y$ por lo tanto, con los países limítrofes y del Perú): "En la Argentina el relato nacional habla de que la población del país es el resultado de un "crisol de razas". Pero mientras en el imaginario brasileño las "razas" que se habían mezclado fueron los blancos, los indígenas y los afrodescendientes, en la Argentina se trata de una mezcla de "razas" solamente europeas. Los argentinos, según ese relato, descenderían de los barcos. Carecen de sangre indígena. Ese régimen de invisibilización de la diversidad explica que cuando un historiador afirma que el General San Martín fue hijo de una india guaraní se genere
Porque no están cercanos culturalmente, y por la historia, aparte, los que estamos sentados acá somos todos hijos o nietos de inmigrantes europeos, no y vos tenés un boliviano del altiplano o un peruano, no tiene una cultura europea como la que tenemos nosotros (Grupo Focal compuesto por docentes de escuelas secundarias privadas, coordinado por miembro del equipo de investigación UBACYT, 30 de abril de 2005).

Resulta importante señalar que en el imaginario acerca de las migraciones "tradicionales", plasmado en las entrevistas citadas, se evidencian recuerdos pero también olvidos. De esta manera, los conflictos sociales, económicos y políticos que involucraron a aquellos migrantes de ultramar y las consecuentes medidas estatales (tales como, por ejemplo, La Ley de Residencia $^{6}$ y la Ley de Defensa Social ${ }^{7}$ ) no forman parte del relato idílico de la época ${ }^{8}$. De modo tal que, coincidiendo con la perspectiva teórica que postula el cuestionamiento sobre el beneplácito con que fueran recibidas las "migraciones tradicionales" y retomando la idea de las migraciones como un "problema social", Domenech (2011) sostiene que la inmigración es construida, por el Estado Argentino, desde sus inicios, como problema - fundamentalmente- a partir de

un escándalo. Las versiones populares de una nacionalidad cruzada por lo indígena (muy fuertes en algunas provincias) permanecieron invisibilizadas por la hegemonía aplastante de la concepción porteña de que los argentinos descienden de los barcos" (Grimson, 2006, 2).

6 Sancionada en 1902, establecía que el Poder Ejecutivo podía expulsar a todo extranjero que hubiese sido condenado o perseguido por la justicia de otros países o que comprometiera la seguridad nacional o perturbara el orden público.

7 Ley, sancionada en 1910, que establecía la expulsión de extranjeros y una graduación de sentencias según el "daño" producido por el extranjero.

8 Sobre este tema puede consultarse: Costanzo, G. (2009) "El Diario de las Sesiones y los debates sobre las Leyes de Residencia y de Defensa Social: la criminalización del anarquismo". En Martini, S. y Pereyra, M., La irrupción del delito en la vida cotidiana. Buenos Aires: Biblos. 
la ilegalidad que se le atribuye y que ello se ha arraigado en la manera en que aun hoy las mismas son pensadas, percibidas y representadas 9 .

Asimismo, en este tipo de representaciones sociales, subyace una lógica utilitarista en las relaciones que se establecen entre extranjeros y nativos. En dicha relación funcional o utilitarista, la presencia del migrante debe tener una utilidad o función, ya sea para el migrante o para la sociedad receptora. Así, coincidiendo con Sayad $(2009,104)$ la presencia legítima es la del nativo, mientras que la del migrante “...es la presencia que solo puede ser pensada y concebida, percibida $y$ experimentada como presencia vista de..., a fin que..., en razón de...". De modo tal que, los migrantes de ultramar tenían un fin: construir las bases sociales, económicas y morales de la Nación en formación. Por el contrario, los migrantes actuales cumplirían la función de ser los "chivos expiatorios", culpables de los problemas económicos y sociales que no se pueden solucionar (Mármora 2002). Es así que, muchas veces, los migrantes de países limítrofes y del Perú son representados bajo el prejuicio reiterado de ser "oportunistas", como "competencia laboral" o "usurpadores" de derechos, tales como, la salud o la educación (Cohen 2009) ${ }^{10}$.

9 Excede a los objetivos del artículo el abordaje exhaustivo de la Ley de Migraciones ( $\left.n^{\circ} 25871\right)$ que rige actualmente en la Argentina. Resulta importante comentar que Domenech sostiene que, aunque la misma implique, según sus impulsores, un cambio de paradigma en el modo de entender a las migraciones, ahora atravesado por una perspectiva de derechos humanos, la centralidad de los derechos adquiere un carácter ambivalente, ya que la ley se ve inspirada en un enfoque de "gobernabilidad migratoria", focalizándose fundamentalmente en la necesidad de "controlar" los flujos migratorios (Domenech 2011). Asimismo, se considera que a pesar de las críticas que pueden hacerse de la ley migratoria actual, la misma significó un avance sustancial en materia de reconocimiento de derechos de los extranjeros, sobre todo comparada con la normativa anterior, la denominada, "Ley Videla" que fuera sancionada durante la última dictadura militar y que se regía por la Doctrina de Seguridad Nacional y sobre la que se ha hecho referencia en el artículo.

10 Como indica Cohen (2009), dichas representaciones remiten a estrategias de control, disciplinamiento
Yo creo que el oportunismo del que viene de afuera, - lo que veo yo, no?-, muchas veces viene con la intención de sacar provecho, los que vienen de niveles muy bajos de Bolivia, Perú, vienen a beneficiarse porque hay plan social, porque hay esto, porque hay lo otro, porque la educación es gratuita, muchos vienen a estudiar... me parece que a veces hay un abuso, y eso molesta porque uno está luchando para salir adelante $y$ ve que a otros extranjeros se les dan otras posibilidades y todo se les hace más fácil (Grupo Focal compuesto por docentes escuelas secundarias públicas, coordinado por miembro del equipo de investigación UBACYT, 23 de mayo de 2005).

...yo creo que nosotros estamos acá y pagamos los impuestos y tenemos que tener acceso a todos lo que nos pueda dar el Estado, más allá de que, bueno, o sea, puede pasar que o haya venido una persona o tenga familiares pero, yo te digo esto que vi el otro día en la Maternidad Sardá, fue horrible porque venía gente de otros países y gente de acá, es una maternidad, un hospital excelente y gente de acá no puede tener acceso porque está o gente de otros países o vienen, o más que la gente que va a tener, los familiares van $y$ aparte son muy oportunistas... (Jésica, Empleada administrativa en el sistema judicial, entrevistada por miembro del equipo de investigación UBACYT, 14 de mayo de 2010).

y regulación sobre el accionar del Otro, estableciendo límites a su participación social, económica y política en ámbitos como la educación, salud, trabajo, etc.: "Cuando el extranjero incursiona, transita esos ámbitos, es percibido como quien sustrae un lugar, se apropia indebidamente de los beneficios de un servicio público. El nativo se considera víctima de ese comportamiento invasor, el extranjero adquiere la dimensión del agresor. - Regular ese tránsito, poner freno a esa invasión, requiere de estratégicos dispositivos de control que evite ese hacer en libertad" (Cohen 2009, 24). 
En conclusión, como puede leerse en los tramos de entrevistas reseñados, al relato positivo y sesgado (teniendo en cuenta que se trata de una reactualización de un discurso que en el momento en que se producían las oleadas migratorias de Europa distaba de ser positivo) se contraponen percepciones de las migraciones regionales recientes, como aquellas con casi nulos aspectos positivos que aportar, fortaleciendo un proceso espiralado de estigmatización y construcción negativa de la otredad migrante.

\section{JERARQUIZACIÓN DE CULTURAS Y RACISMO CULTURAL}

En el proceso de construcción de la otredad migratoria, las sociedades receptoras o "de llegada" recurren a elementos del pasado, reactualizándolos en el presente. En los tiempos actuales, en los que se enaltecen la diversidad $y$ se pregona el respeto por el otro, los discursos biologicistas son desplazados por aquellos que asumiendo posturas tolerantes, consideran que las diferencias entre migrantes y nativos son de índole cultural. Es decir, se trata de "pautas culturales" y "costumbres" diferentes. No obstante, las "reales" diferencias que pudieran existir entre los miembros de una comunidad nacional y otra (ello sin analizar las múltiples diversidades que al interior de cada comunidad de este tipo existen), esta clase de representaciones sociales basadas en las diferenciaciones culturales pueden entrañar un discurso cargado de cierto grado de estigmatización del "otro". En este sentido, al analizar las representaciones de los nativos, respecto de los migrantes llegados a Argentina desde la segunda mitad del siglo xx, se encuentran imágenes sobre los extranjeros portadores de estigmas y que señalan sus identidades nacionales y sus "culturas" como inferiores a la propia.

$-\mathrm{C}^{11}$ : Si ustedes tuvieran que pensar, a ver, imaginen en sus cabezas, quizás algo me pueden decir, características que representen a los inmigrantes.

11 La letra "C" indica que quien está hablando es la coordinadora del grupo focal.
—Su nivel cultural es también bajo.

—Les falta cultura general de sus países de origen (Grupo focal compuesto por docentes de escuelas primarias públicas, coordinado por miembro de equipo de investigación uвacyт, 16 de mayo de 2005).

-C: ¿Dicen que el peruano es más violento?

- Con respecto al boliviano, sí, es muy violento. Es más reclamativo también (Grupo focal compuesto por docentes de escuelas secundarias públicas, coordinado por miembro de investigación Uвасүт, 10 de mayo de 2007).

—C: los bolivianos...

—Ahí sí, son trabajadores. Son muy religiosos.

—Amables.

- Son sucios (Grupo focal compuesto por docentes de escuelas primarias privadas laicas, coordinado por miembro del equipo de investigación uвaсүт, 09 de noviembre de 2005).

—C:¿Paraguayos...qué podemos decir?

— iSon re machistas! Chantas. Vagos son (Grupo focal compuesto por docentes de escuelas primarias privadas religiosas, coordinado por miembro del equipo de investigación uвacyt, 01 de junio de 2005).

Estas imágenes acaban sosteniendo una "jerarquización de culturas", que presentes en las representaciones sociales de miembros de instituciones, como la escuela o la justicia, adquieren relevancia, dada la función de socialización de una y de reconocimiento de derechos de la segunda. No considerar discursivamente al migrante como un igual, significa al menos una advertencia respecto a las posibilidades reales de llevar adelante una educación de tipo intercultural y respetuosa de la diversidad. De 
igual manera, representaciones del poder judicial, como las que se han presentado, en tanto "recetas para el accionar", pueden resultar preocupantes dado que, si bien, se presume la igualdad de todos(as) ante la ley, quienes la administran portan percepciones respecto a los migrantes que podrían implicar interpretaciones de las legislaciones de modo diferencial.

- Por ahí el que más problemas tiene es Paraguay, sacarles el acentito que puedan tener.

- Hay que tener en cuenta la personalidad según el país de origen. Un boliviano va a tener una raíz temperamental distinta a la de un peruano, que ya viene con intenciones más de superación, de logros.

-Es como ella decía, yo tuve nenes que hablé con la mamá para que les hable en castellano para que no hable tanto en guaraní (Grupo focal compuesto por docente de escuelas primarias públicas, coordinado por miembro de equipo UBAcyT, 16 de mayo de 2005).

Tiene que ver más con cuestiones culturales. No es un delito, pero se vive denunciando a la comunidad boliviana en la zona de Liniers porque tienen otro tipo de costumbres de alimentación, de fiestas populares $y$ de lo que sea. Y tienen otro cuidado y otra manera de llevarse con lo público, que hay un choque cultural muy importante, sucios, que ensucian bienes públicos; que tiran deshechos en la vía pública; cortan calles (Secretario, Director Oficina de atención a víctimas, Pedro, entrevistado por miembro del equipo de investigación uвасүт, 23 de agosto de 2011).

Creo que puntualmente es la idiosincrasia de ellos [paraguayos], si creo que es un factor, por lo general, se generan por el tema de los festejos, son personas que son muy bebedoras $y$ tienen una idiosincrasia que siempre tienen que estar armados con algún cuchillo o armados con armas de fuego y entonces creo justamente que es por la cultura de ellos (Marta, Secretaria, entrevistada por miembro del equipo de investigación UBAсүт, 23 de junio de 2010).

En el caso del universo justicia, dada la función social de dicha institución, la cuestión cultural también aparece vinculada con las explicaciones acerca de los motivos por los cuales los migrantes delinquirían o cometerían contravenciones. De este modo, puede leerse:

La verdad que no, creo que en parte tiene que ver con sus costumbres o sea, por ejemplo, la forma de vida que llevan los bolivianos en Liniers creo que es parte de sus costumbres de vender en la calle sus comidas típicas, o sea creo que ellos están acostumbrados a eso, pero acá nosotros tenemos una reglamentación que no lo permite (...) hacen lo que quieren, en Liniers vos tenés un puesto al lado del otro en la calle, todos vendiendo donde la gente quiere bajar por la calle para poder caminar por ahí y con miedo, no sabes quién te va a robar, si te sacan la cartera (Maribel, secretaria, entrevistada por miembro del equipo de investigación uвacyt, 19 de agosto de 2010).

Estas afirmaciones entrañan cierto grado de rechazo por la alteridad cultural, por la cultura "otra" que no solo es diferente de la propia sino leída como inferior y por ello, estigmatizada. Este rechazo de la alteridad cultural es un elemento propio de lo que algunos autores denominan "racismo cultural" (Wieviorka 2002) o "racismo diferencialista" (Balibar 1991). En las expresiones del racismo cultural:

El Otro, desde este punto de vista, es definido por el grupo "racista" como diferente por su tradición, su nación, su religión, su lengua, su historia, y esta diferencia, irreductible constituiría una amenaza tal para el grupo en cuestión que este, en contraposición, reclama 
discursos y prácticas de segregación, de expulsión o de destrucción (Wieviorka 2002, 290).

En esta lógica de diferenciación se trata de mantener al "otro" a distancia, imputándoseles, en este caso a los migrantes, características estigmatizantes: como las de ser "sucios", "bebedores" o "peligrosos", "violentos", entre otros.

Bueno, pero, por ejemplo, en el caso de la violencia familiar los tipos delictivos que pueden estar más asociadas a las prácticas domésticas o a la cultura puede ser, Paraguay, seguramente es cierto, un país que por determinación histórica se ha vuelto machista, después de la triple alianza o la violencia, puede ser porque eran pocos, entonces puede ser que eso sea de determinadas pautas culturales que se traducen (Gabriel, Auxiliar, entrevistado por miembro del equipo de investigación uвacyt, 26 de junio de 2010).

En suma, retomando aspectos ligados a la "idiosincrasia" o a las pautas culturales del colectivo en cuestión, se entabla una relación entre migrante y nativo definida por la suspicacia o la sospecha. Además, desde la perspectiva de los entrevistados, el migrante es un sujeto que no inspira confianza debido a que confluyen en él, la presencia y la ausencia.

Empleando una categoría de Bauman (1998), ocurre que el extranjero forma parte de los "innombrables". Al no encontrarse físicamente del otro lado de la frontera, obligan a compartir "nuestros" espacios con ellos. Esta ambigüedad, inherente a ellos, les confiere un halo de peligrosidad porque supone cierta incerteza de su accionar, amenazan la posibilidad de sociabilidad porque pueden ser tanto un amigo como un enemigo, "...lleva consigo la incurable enfermedad de la incongruencia múltiple”, es una anomalía (Bauman 1998, 118).

Lo anterior presume una serie de estigmas que recaen sobre el extranjero que “... lo mejor que puede ser es un "amigo a prueba" $y$ en permanente verificación, una persona observada y bajo la presión de ser alguien más que él, avergonzado de su culpabilidad por no ser lo que debe ser" (Bauman 1998, 117). En términos de Schütz, por su calidad de forastero, recae sobre el migrante el pecado original de la llegada tardía, el no pertenecer "desde siempre y para siempre" a la Nación en la que reside (Bauman 1998, citado en González 2013, 121).

Es debido a que se enmarca en una relación asimétrica de dominación (que involucra al nativo y al migrante) que, si bien, el racismo cultural o diferencialista apela a ciertas diferencias culturales, culmina esencializando alteridades culturales de forma estigmatizadora. En el racismo cultural o "racismo sin razas": "la cultura puede funcionar también como una naturaleza, especialmente como una forma de encerrar a priori a los individuos y a los grupos en una genealogía, una determinación de origen inmutable e intangible" (Balibar 1991, 38).

Es así que las representaciones sociales que apelan a cierto racismo cultural y por el cual se recurre a atributos negativos y estigmatizantes ("sucios", "violentos", "machistas", "chantas") para referirse a migrantes sudamericanos, naturalizan un determinado origen "cultural", pero también refuerzan una dinámica espiral de estigmatización, desigualdad social y exclusión de los mismos. En este punto, se coincide con Wieviorka $(2002,288)$ cuando sostiene que "la diferencia cultural se combina con fuertes desigualdades sociales, va a la par con un difícil acceso al empleo, a la salud, a la vivienda, la escuela y las dos dimensiones - la social y la cultural- parecen reforzarse mutuamente.

Recapitulando, lo que los nativos categorizan como "cultura migrante" resulta ser una serie de estereotipos, estigmas, preconceptos e ideas esencializantes que poco o nada tienen que ver con "los migrantes", pero que se engloban en dicha categoría. Así, se subsumen en la figura de "el migrante", con sus matices según la nacionalidad, una serie de prejuicios que son re-actualizados en las relaciones cotidianas que se entablan entre migrantes $y$ nativos ${ }^{12}$.

12 En ese sentido, se refiere al término de extranjeridad "...como esa categoría que agrupa a quienes nacieron más allá de las fronteras, para constituirse como un estado particular de lo diferente, de aquello respecto de lo cual el nativo 


\section{DEL RACISMO CULTURAL A LA DISPUTA POR LOS} DERECHOS

Llegados a este punto en la reflexión, resta preguntarse por posibles explicaciones que permitan aprehender los intereses que se intentan preservar y los conflictos que subyacen a la construcción negativa por parte de los nativos de la "cultura" del migrante internacional actual. Sobre esta cuestión, a partir de lo que se ha podido evidenciar en el trabajo de campo realizado en estas investigaciones, la presencia física de los extranjeros interpela a los nativos acerca del tema de la inclusión y la exclusión de los mismos como miembros de la comunidad nacional y por tanto, como merecedores de derechos. Por lo tanto, la definición de la "pertenencia", en el sentido de Mezzadra, se torna conflictiva y los migrantes un "problema social".

... la cuestión de la exclusión de los migrantes del espacio jurídico, político y simbólico del Nosotros constituido por el conjunto de los sujetos titulares plenos de los derechos de ciudadanía ocupa una importancia estratégica tanto en la teoría como en la práctica: más aun en una época en la que cada configuración 'identitaria'...parece investida de múltiples tensiones, circunstancia que favorece la difusión de tendencias de repliegue defensivo y reactivo en pequeñas patrias más o menos abiertamente racistas $(2005,98)$.

La situación se complejiza aun más, en el caso argentino, porque como se ha mencionado, la sanción de la Ley migratoria 25871

permanece alerta. La extranjeridad se presenta como categoría de lo extraño, de lo intruso y resulta de un complejo proceso de expropiación de los atributos individuales y de asignación de atributos del colectivo, como tal, el sujeto es invisibilizado como individuo y resignificado como nacionalidad o etnia. Este proceso de expropiación $y$ resignificación termina constituyéndose en un acto de dominación sobre el otro. Es posible resignificarlo porque hay una condición previa de distribución desigual de poder entre las partes" (Cohen 2012, 202). irrumpe en el escenario social. Dicha ley resulta di sruptiva, debido a que entra en tensión con el tipo de representaciones sociales como las que se presenta en el artículo. La normativa actual asume como uno de sus objetivos principales "...dar cumplimiento a los compromisos internacionales de la República en materia de derechos humanos, integración y movilidad de los migrantes" (art. 3, Ley 25871), adoptando así una perspectiva que privilegia los Derechos Humanos. No obstante, como se observa, cuando la relación entre migrante y nativo se torna "real", aun en el marco de instancias institucionales como la escuela o el poder judicial, pareciera acabarse la "tolerancia multicultural" hacia el otro (Zizek 2008). Tan pronto como el "otro" actúa como un sujeto que desafíe el statu quo y se presente como demandante y titular de derechos, es cuando la retórica multicultural se acaba.

Precisamente, porque somos los que tenemos que tener primer cobija del Estado y después, por supuesto que los demás sí, pero pasa en todos lados del mundo, creo que por reciprocidad, si vas a España $y$ te querés hacer atender en el hospital si no tenés la tarjeta social porque no pagas impuestos, que sé yo, no te van a atender $y$ si vas a cualquier otro país, pasa lo mismo, estamos hablando de países del primer mundo, y si vas a Bolivia, Paraguay, cualquiera, va a pasar lo mismo, pero acá, por ejemplo, vas a un hospital $y$ van personas de diferentes partes de Latinoamérica a atenderse $y$ porque es gratuito $y$ porque $y$ ni siquiera demuestran que viven acá, vienen directamente a... lo he visto en el Hospital Garrahan, por ejemplo, no? Gente, de todas partes, no yo creo, en ese sentido, si, para recibir, creo que para tener derechos primero tenés que tener obligaciones $y$ deberes $y$ muchos vienen $y$ ni tienen obligaciones como ciudadanos ni deberes entonces no pueden pretender tener los mismos derechos que nosotros (Carlos, Fiscal, entrevistado por miembro del equipo de investigación uвacyт, 14 de mayo de 2010). 
Yo también me siento mal cuando quedan argentinos sin trabajar y vos decís ¿Por qué le dieron trabajo a esta persona y no se lo dieron al que está ahí? Digo, yo tuve a los chicos en su momento, buscaban de lo que hubiera y les pedían unos requisitos que más o menos tenían que ser universitarios para ser cadete, ¿sí? y de pronto el extranjero, porque es extranjero consigue trabajo o viene con trabajo (Grupo focal compuesto por docentes de escuelas secundarias públicas, coordinado por miembro de investigación uBacyt, 10 de mayo de 2007).

Esto que me contaba una vecina mía, que es obstetra $y$ trabaja en el Hospital Santojanni y dicen que es común que una vez por mes, cada 20 días aparecen tours de embarazadas bolivianas que, en combis, las traen de allá, vienen 7, 8 embarazadas cuando están ya en el séptimo mes y ya se instalan acá y el chico nace argentino no? Y vienen todas en grupo.

-Acá no hay, no alcanza para la gente de acá, eso lo veo pésimo.

—Los hospitales acá no tiene gasas, no tiene algodón, no tiene nada, hacen paro, no podes atenderte en un hospital público pero la gente de afuera lo puede utilizar, ¡Es injusto!

—Sí, sí que es injusto.

- Tendría que ser bueno para los trabajadores argentinos, para nosotros, los hospitales... o que les cobren algo (Grupo focal compuesto por docentes de escuelas secundarias privadas, coordinado por miembro del equipo de investigación UBacy, 30 de abril de 2005).

Las representaciones sociales que construyen al migrante internacional como otredad negativa, completan el círculo de la estigmatización, así como, el proceso de exclusión al vincular dicha imagen estereotipada $y$ moralizante con la definición de quién resulta ser merecedor de qué bienes económicos y derechos sociales. En tanto miembros de instituciones estatales, docentes y miembros del poder judicial, colaboran en la reproducción del imaginario del migrante como un ciudadano, al menos, de segunda categoría.

Debería haber un control, en cuanto a la inmigración, un poco mayor por parte del Estado ....sinceramente, en muchos sentidos uno trata de ser solidario $y$ de pensar, están muy mal en su país y vienen acá. Pero también hay muchos argentinos que pierden oportunidades laborales, pierden muchas oportunidades porque se las dan a ellos. En cierta manera la solidaridad empieza por uno (Grupo Focal compuesto por docentes de escuelas secundarias privadas laicas, coordinado por miembro del equipo de investigación UBACYT, 14 de junio de 2005).

En suma, en la relación conflictiva que puede establecerse entre migrantes $y$ nativos persiste la idea de ciudadanía clásica que vincula aquella con la pertenencia a una Nación. Nacionalidad y ciudadanía tienden a equipararse. En esa operación que homologa una y otra categoría, el Estado aparece como el representante de la identidad nacional y por lo tanto, el principal garante de los derechos de los nativos. Esa exigencia de un Estado con mayor presencia, más "nacionalista", se traduce en el requerimiento de establecer un tipo de política migratoria que se contradice con la perspectiva de derechos humanos de la Ley 25871.

...creo que esto tiene mucho que ver también con que tenemos un Estado, me parece que no es un Estado nacionalista, no es un Estado que proteja justamente, sus instituciones ¿no? y obviamente a la población argentina, un Estado que no cuida el ingreso de extranjeros, no hay recaudos ni limitaciones al ingreso de extranjeros, hay otros países que te exigen una serie de cosas para poder ingresar $y$ por lo menos estar ... si vos me decís que tenés un país que funciona el $100 \%$ como tiene que funcionar $y$ 
seríamos un país que estaríamos dentro de los del primer mundo te digo, bueno, quizás podrían llegar a ser mucho más abierto en cuanto a la inmigración, controlando el equilibrio ¿no? esto del equilibrio en cuanto a que no afecte a la economía, que no afecte porque justamente al tener más ingreso de inmigrantes te puede llegar a afectar el funcionamiento en cuanto a lo laboral porque empezás a tener índices de desempleo (Maribel, secretaria, entrevistada por miembro del equipo de investigación UBACYT, 23 de junio de 2010).

-Acá aparte las fronteras están totalmente desprotegidas.

-Bueno están porque nosotros las descuidamos.

-C: ¿y que debería hacer el Estado con las fronteras?

-Y bueno, primero proteger las fronteras, hacer lo que hacen en otros países, una visa, control de qué voy a hacer. Que tengan un proyecto. Un proyecto de vida (Grupo Focal compuesto por docentes de escuelas secundarias públicas, coordinado por miembro de investigación UBACYT, 10 de mayo de 2007).

En conclusión, la nacionalidad se convierte en el límite para el acceso a derechos al homologarse con la categoría de ciudadanía. De este modo, frente al fenómeno migratorio, la condición ciudadana es asociada directamente a la pertenencia a un determinado Estado nacional. Asimismo, como puede verse en los tramos discursivos citados anteriormente, es al EstadoNación al que la sociedad receptora interpela para el aseguramiento de sus derechos.

De modo tal que, contradiciendo los principios de universalidad, integrabilidad $y$ progresividad de los derechos humanos, persisten en las representaciones sociales de docentes y miembros del poder judicial, discursos excluyentes. En este sentido, la extranjeridad del no-nativo posibilita que sea, al menos, "pensable", establecer restricciones y/o negar el reconocimiento de derechos de los migrantes.

\section{REFLEXIONES FINALES}

En este artículo se buscó analizar qué representaciones sociales, en instituciones tales como la escuela y el poder judicial, se construyen acerca de la identidad nacional, así como, las consecuencias que implican en los imaginarios acerca del reconocimiento y valorización de la cultura y las identidades de los migrantes internacionales. En suma, se trató de recuperar y repensar la idea de Nación, evidenciando cómo continúa operando en los modos en que se construye sentido; es decir, ideas, imaginarios $y$ representaciones sociales, sobre la identidad nacional y la alteridad en las sociedades actuales. Asimismo, dicha constitución identitaria se transfigura no solamente en un tratamiento de la diversidad migratoria como ajena y cargada con valoraciones de claro tinte negativo, sino también en posturas respecto a "quienes tienen derecho a tener derechos".

En este punto, resulta relevante hacer referencia - una vez más - a la forma en que el Estado-Nación argentino construyó la identidad nacional. Esta se edificó por oposición a lo latinoamericano y mestizo, así como se configuró en el imaginario, la idea de una Nación de matriz europea. En este sentido, entre los resultados de las investigaciones sobre las que se basa este artículo, se ha podido evidenciar que la otredad migrante aparece en las representaciones sociales de los entrevistados de modo diferencial, según se trate de las migraciones transoceánicas de fines del siglo xix y principios del xx o de las recientes, fundamentalmente regionales. Las primeras, son evidenciadas como aquellas que construyeron la Nación, las que llegaron para trabajar honestamente, a asentarse, a conformar una comunidad. Se produce así un "olvido", tanto de los aportes migratorios regionales, coincidentes con las olas migratorias europeas, como de los grupos originarios.

Asimismo, en otras de las dimensiones abordadas, como ha podido ilustrarse con los testimonios, persiste un "racismo cultural", en los términos definidos por Wieviorka (2009), 
que intenta disimular un discurso racista $y$ prejuicioso, ya no recurriendo a argumentos biologicistas, sino anclándolo en elementos "culturales", de "costumbres", de "idiosincrasia", que explicarían los comportamientos de los migrantes, catalogados como desviados. La cultura en este caso ligada a la identidad nacional- es jerarquizada, etiquetando a la de los migrantes como inferior y desviada, frente a la nativa, que es representada como superior y normal.

Esta negativización de la "identidad" y la "cultura migrante", que puede leerse en diversos testimonios de los entrevistados, dejan entrever que lo que subyace a dicha construcción negativa se relaciona no solo con un distanciamiento en términos de "brecha cultural" irreductible, entre los miembros de la sociedad receptora y los migrantes internacionales, sino ante todo responde a una disputa de intereses, en donde lo que se pone en juego es la definición de pertenencia en términos de goce de bienes económicos y acceso a derechos sociales.

En este sentido, docentes y miembros del poder judicial, participan de un entramado institucional en el que se re-produce un ideario social acerca del migrante como ciudadano, al menos, de categoría inferior a la de los nativos.

Frente al nuevo marco normativo, que regula a la política migratoria y los derechos $y$ obligaciones de los migrantes que llegan a la Argentina, se abren nuevos debates acerca de la manera en que el Estado administra la diversidad migratoria. Al respecto, el art. 6 de la Ley de Migraciones resulta esclarecedor:

El Estado en todas sus jurisdicciones, asegurará el acceso igualitario a los inmigrantes $y$ sus familias en las mismas condiciones de protección, amparo $y$ derechos de los que gozan los nacionales, en particular lo referido a servicios sociales, bienes públicos, salud, educación, justicia, trabajo, empleo y seguridad social (Ley 25871).

En esa tarea, sin duda, la escuela y el sistema judicial cumplen un rol fundamental. La escuela, porque es allí donde los niños nativos y migrantes asisten no solo para aprehender conocimientos de la educación básica, sino también para ser socializados en valores $y$ creencias. La escuela, aun con sus transformaciones y mudanzas, continúa siendo la institución de socialización primaria básica. Por su parte, el poder judicial es el espacio donde los derechos deben ser reconocidos y protegidos siguiendo los principios de universalidad $y$ progresividad que las legislaciones locales e internacionales determinan. El interrogante, que aun no se ha podido responder, dado que la implementación de la ley resulta reciente (su reglamentación se logró recién en el año 2010), es la posibilidad, en aras del objetivo de acceso real y efectivo a derechos de los migrantes, deconstruir los imaginarios y representaciones sociales presentes en ambas instituciones $y$ que se ha intentado presentar $y$ analizar en las páginas precedentes.

\section{BIBLIOGRAFÍA}

LIBROS

Anderson, Benedict. 1993. Comunidades imaginarias: reflexiones sobre el origen y la difusión del nacionalismo. México: FCE.

Balibar, Etienne. 1991. Raza, Nación y clase. Madrid: IEPALA.

Balibar, Etienne. 2005. Violencias, identidades y civilidad. Barcelona: Gedisa.

Bauman, Zigmunt. 1998. "Modernidad y ambivalencia". En Las consecuencias perversas de la modernidad, compilado por Josetxo Berian, 73-119. Barcelona: Ed. Anthropos.

Benencia, Roberto. 2003. "Apéndice. La inmigración limítrofe”. En Historia de la inmigración de la Argentina, editado por Fernando Devoto, 433-484. Buenos Aires: Sudamericana.

Calhoun, Craig. 2008. Nacionalismo. Buenos Aires: Libros del Zorzal.

Cohen, Nestor. 2010. Representaciones de la diversidad: trabajo, escuela y juventud. Buenos Aires: Ediciones Cooperativas.

Cohen, Nestor. 2009. "No es solo cuestión de migrantes: migraciones externas y exclusión social". En Conflictos y expresiones de la desigualdad y la exclusión en 
América Latina, Sebastián Goinheix. Buenos Aires: El Aleph.

Cohen, Nestor y Carolina Mera. 2005. Relaciones interculturales: experiencias y representación social de lo migrantes. Buenos Aires: Antropofagia.

Costanzo, Gabriela. 2009. "El diario de las sesiones y los debates sobre las Leyes de Residencia y de Defensa Social: la criminalización del anarquismo". En La irrupción del delito en la vida cotidiana, editado por Stella Martini y Marcelo Pereyra. Buenos Aires: Biblos.

Courtis, Corina. 2006. "Hacia la derogación de la Ley Videla: la migración como tema de labor parlamentaria en la Argentina de la década de 1990". En Migraciones regionales hacia la Argentina: diferencia, desigualdad y derechos, editado por Jelin $y$ Grimson. Buenos Aires: Prometeo.

Crosa Pottilli, Julia, Silverstein, Yael y Tavernelli, Romina. 2009. "De la jerarquización de las naciones a la clasificación de los sujetos: representaciones sociales que perpetuan un orden exclusor". En Representaciones sociales de la diversidad: trabajo, escuela y juventud, editado por Cohen, Néstor. Buenos Aires: Ed. Cooperativas.

Devoto, Fernando. 1992. Movimientos migratorios : historiografía y problemas. Buenos Aires: Centro Editor de América Latina.

Díaz Polanco, Héctor. 2006. Elogio de la diversidad: globalización, multiculturalismo y etnofagia. México: Siglo xix.

Domenech, Eduardo. 2010. "La 'nueva política migratoria' en la Argentina: las paradojas del programa 'Patria Grande'. En Migraciones internacionales contemporáneas. Estudios para el debate, compilado por Cynthia Pizarro. Buenos Aires: ciccus.

Domenech, Eduardo. 2011. "Crónica de una 'amenaza' anunciada. Inmigración e 'ilegalidad': visiones de Estado en la Argentina contemporánea". En La construcción social del sujeto migrante en América Latina: prácticas, representaciones y categorías, compilado por Bela
Feldman-Bianco, Liliana Rivera Sánchez, Carolina Stefoni, Marta Inés Villa Martínez, Quito: clacso, 31-177.

Grimson, Alejandro. 2006. "Nuevas xenofobias, nuevas políticas étnicas en la Argentina". En Migraciones regionales hacia la Argentina. Diferencia, desigualdad $y$ derechos. Alejandro Grimson \& Elizabeth Jelin (comps.). Buenos Aires: Prometeo.

Ibáñez, Jesús. 1992. "El grupo de discusión: técnica y crítica”. En Más allá de la sociología, coordinado por Jesús Ibáñez. España: Siglo xxı.

Jodelet, Denise. 1986. "La representación social: fenómenos, concepto y teorización” En Psicología Social, compilado por Serge Moscovici, 468-510. Barcelona: Paidós.

Mármora, Lelio. 2002. Las políticas de migraciones internacionales. Buenos Aires: Paidós.

Martinez Pizarro, J., Cano Christin, V., y Contrucci, M. S. 2014.Tendencias y patrones de la migración latinoamericana y caribeña hacia 2010 y desafíos para una agenda regional. Santiago de Chile: CEPAL.

Pacecca, María Inés. 2006. "Migraciones interculturalidad". En Diversidad cultural e interculturalidad. Editado por Jure, A. Buenos Aires: Prometeo.

Santamaría, Enrique. 2010. La incógnita del extraño. Barcelona: Anthropos.

Strauss, Anselm, y Juliet Corbin. 2002. Bases de la investigación cualitativa: técnicas y procedimientos para desarrollar la teoría fundamentada. Colombia: Univ. de Antioquia.

Wieviorka, Michel. 2002. El racismo:una introducción. Barcelona: Gedisa.

Zizek, Slavoj. 2008. En defensa de la intolerancia. Madrid: Ediciones Sequitur.

\section{PUBLICACIONES PERIÓDICAS}

González, Anahí, y Gabriela Plotnik. 2011. “Es posible una educación para la integración? Discursos y experiencias interculturales en aulas argentinas". Politicas Educativas 4, n. ${ }^{\circ}$ 2: 83-96. 
González, Anahí. 2012. "Representándose 'al otro migrante': el poder judicial como institución estatal nacional". Revista Derecho y Ciencias Sociales, n. ${ }^{\circ}$ : 11-113.

Mezzadra, Sandro. 2012. "Capitalismo, migraciones y luchas sociales. La mirada de la autonomía". Revista Nueva Sociedad, n. $237: 159-178$.

Sayad, Abdelmalek. 2009. "Estado, Nación e inmigración”. Apuntes de investigación, n. ${ }^{\circ}$ 13: 101-116.

\section{ENTREVISTAS}

Carlos, Fiscal, entrevistado por miembro del equipo de investigación UBACYT, 14 de mayo de 2010, San Justo, Gran Buenos Aires.

Gabriel, Auxiliar, entrevistado por miembro del equipo de investigación UBACYT, 26 de junio de 2010, Ciudad Autónoma de Buenos Aires.

Jésica, Empleada administrativa en el sistema judicial, entrevistada por miembro del equipo de investigación UBACYT, 14 de mayo de 2010, Ciudad Autónoma de Buenos Aires.

Juan, Fiscal, entrevistado por miembro del equipo de investigación UBACYT, 01 de agosto de 2010, Ciudad Autónoma de Buenos Aires.

Mariano, Prosecretario, entrevistado por miembro del equipo de investigación UBACYT, 18 de agosto de 2010, Ciudad Autónoma de Buenos Aires.

Maribel, Secretaria, entrevistada por miembro del equipo de investigación UBACYT, 19 de agosto de 2010, Ciudad Autónoma de Buenos Aires.

Marta, Secretaria, entrevistada por miembro del equipo de investigación UBACYT, 23 de junio de 2010, San Martín, Gran Buenos Aires.

Pedro, entrevistado por miembro del equipo de investigación Uвасүт, 23 de agosto de 2011, Ciudad Autónoma de Buenos Aires.

Silvina, Escribiente, entrevistada por miembro de equipo de investigación UBACYT, 18 de agosto de 2010, Ciudad Autónoma de Buenos Aires.

\section{OTRAS FUENTES}

Grupo focal compuesto por docentes de escuelas primarias públicas, coordinado por miembro del equipo de investigación UBACYT, 18 de mayo de 2005, Ciudad Autónoma de Buenos Aires.

Grupo Focal compuesto por docentes de escuelas secundarias privadas, coordinado por miembro del equipo de investigación UBACYT, 30 de abril de 2005, Ciudad Autónoma de Buenos Aires.

Grupo Focal compuesto por docentes de escuelas secundarias públicas, coordinado por miembro del equipo de investigación UBACYT, 23 de mayo de 2005, Ciudad Autónoma de Buenos Aires.

Grupo Focal compuesto por docentes de escuelas primarias públicas, coordinado por miembro de equipo de investigación UBACYT, 16 de mayo de 2005, Ciudad Autónoma de Buenos Aires.

Grupo Focal compuesto por docentes de escuelas primarias privadas y laicas, coordinado por miembro del equipo de investigación UBACYT, 09 de noviembre de 2005, Ciudad Autónoma de Buenos Aires.

Grupo Focal compuesto por docentes de escuelas primarias privadas religiosas, coordinado por miembro del equipo de investigación UBACYT, 01 de junio de 2005, Ciudad Autónoma de Buenos Aires

Grupo Focal compuesto por docentes de escuelas secundarias privadas, coordinado por miembro del equipo de investigación UBACYT, 30 de abril de 2005, Ciudad Autónoma de Buenos Aires.

Grupo Focal compuesto por docentes de escuelas secundarias privadas laicas, coordinado por miembro del equipo de investigación UBACYT, 14 de junio de 2005, Ciudad Autónoma de Buenos Aires.

Grupo Focal compuesto por docentes de escuelas secundarias públicas, coordinado por miembro de investigación UвACүт, 10 de mayo de 2007, Ciudad Autónoma de Buenos Aires.

Fecha de ingreso: 06/07/2015

Fecha de aprobación: 15/12/2015 
